\title{
Zonas de pasto y gestión de marjales en balad Balansiya. Unas hipótesis para el estudio de la ganadería andalusí desde la arqueología del paisaje
}

\author{
Grazing areas and management of wetlands in balad Balansiya. Some \\ hypotheses for the study of Andalusi livestock \\ from Landscape Archaeology
}

Ferran ESQUILACHE

\begin{abstract}
Author:
Ferran Esquilache

Universitat Jaume I (Castellón, Spain)

ferran.esquilache@gmail.com

https://orcid.org/0000-0003-2971-2469

Date of reception: 15/04/21

Date of acceptance: 28/05/21

\section{Citation:}

Esquilache, F. (2021). Zonas de pasto y gestión de marjales en balad Balansiya. Unas hipótesis para el estudio de la ganadería andalusí desde la arqueología del paisaje. Anales de la Universidad de Alicante. Historia Medieval, (22), 165-189.

https://doi.org/10.14198/medieval.19499

Funding: Este trabajo se enmarca dentro del proyecto "La gestión de la herencia agraria andalusí: modificaciones y trasformaciones realizadas en espacios irrigados tras la conquista cristiana en el reino de Valencia, siglos XIII-XVI (UJI-A2018-07)", financiado por la Universitat Jaume I de Castelló.
\end{abstract}

Acknowledgments: Agradezco a Vicent Royo y a los evaluadores externos de la revista sus consejos para mejorar este trabajo.

\section{(C) 2021 Ferran Esquilache}

Licence: This work is licensed under a Creative Commons Attribution 4.0 International License (CC BY 4.0).

\section{RESUMEN}

La ganadería andalusí es un tema difícil de estudiar por la falta de fuentes escritas. Sin embargo, combinando la documentación de época cristiana y análisis del paisaje se puede aportar información que permite presentar hipótesis. Este es el objetivo del presente trabajo, identificar algunas zonas de pasto en territorio valenciano y, a través de análisis paisajísticos, presentar hipótesis sobre su uso y gestión en época andalusí. En este sentido, se propone que había un movimiento del ganado local por dentro de los términos de las alquerías, buscando combinar distintos tipos de pasto - de marjal y de montañapara complementar la dieta de los animales y no agotar los pastos. Aunque es posible que también se moviesen por los términos de las aljamas vecinas gracias a los pactos entre comunidades rurales. Además, se plantea la posibilidad de que hubiese habido trashumancia de ganado entre las montañas del interior y los marjales de la costa, basada en acuerdos tribales, especialmente entre las montañas del sistema Ibérico y los marjales de la costa valenciana. Finalmente, se identifica una privatización de los espacios comunales durante el período final andalusí, con la formación de rahales de las elites para su explotación al margen de las alquerías. 
PALABRAS CLAVE: ganadería; pastos; trashumancia; Valencia; al-Andalus.

\section{ABSTRACT}

Researching on Andalusi animal husbandry results quite difficult due to the lack of specific written sources. However, the combination of written documents of the Christian period and the analysis of the landscape allows us to submit some hypothesis. This paper seeks to identify some grazing areas of the Valencian territory and, thanks to land analysis, introduce an hypothesis about their uses and management during the Andalusi period. It is proposed that there was a movement of local livestock within the terms of villages (alquerías), seeking to combine different types of grasslands-marshy and mountain — to complement the diet of the animals and not exhaust the pastures. Nevertheless, it is possible that they also move the livestock through the terms of the neighboring villages, thanks to agreements between rural communities. Besides it is considered the possibility of transhumance between inner mountains and coastal wetlands based on tribal agreements, especially between the mountains of the Iberian System and the wetlands of the Valencian coast. Finally, it is identified a privatization of communal areas during the final Andalusi period through the formation of rahales for the elites, outside the villages. KEYWORDS: livestock; pastures; transhumance; Valencia; al-Andalus.

El conocimiento de los espacios de cultivo andalusíes ha avanzado de una forma extraordinaria en las últimas décadas. Sobre todo por lo que respecta a espacios irrigados, que no solo eran la parte más importante en la mayoría de los agrosistemas andalusíes según la interpretación que se ha venido haciendo hasta ahora, sino también los más fáciles de estudiar por su mejor conservación a lo largo del tiempo. También los espacios de secano se han tenido cada vez más en cuenta, a pesar de las dificultades que existen para su identificación y, precisamente por eso, de momento se conocen un poco mejor los cultivos arbóreos en terrazas que los campos abiertos de cereal. Sin embargo, la ganadería sigue siendo la parte más desconocida de los diversos tipos de agrosistemas existentes en al-Andalus, como consecuencia de la dificultad que entraña su estudio por los pocos rastros que deja en las fuentes escritas y, en cierta medida, también a nivel arqueológico. Lo que explica el escaso interés que ha mostrado por ella la historiografía hasta el momento (Cara, 2009; García y Moreno, 2018). También es cierto que, desde hace algún tiempo, se han venido haciendo trabajos de diversa índole al respecto, muy especialmente sobre la Granada nazarí; y que la arqueozoología está aportando algunos conocimientos muy útiles últimamente (García et al., 2021), sin ser una técnica nueva, pero todavía queda mucho por saber. 
Diversos investigadores han advertido recientemente de la necesidad de integrar la ganadería en el análisis de los diversos agrosistemas andalusíes, puesto que sin ella el sistema de explotación agropecuaria resulta incompleto y, además, afecta a su propio funcionamiento por la simbiosis existente entre agricultura y ganadería (Malpica et al., 2017; García y Moreno, 2018). En este sentido, el primer objetivo de este trabajo es intentar identificar algunas de las áreas de pasto en el territorio valenciano de época andalusí en relación con las zonas de cultivo. Especialmente por lo que respecta a los marjales litorales, que han sido considerados tradicionalmente como marginales por su escaso aprovechamiento para la agricultura en al-Andalus, pero que parecen haber tenido mucha importancia para la economía campesina mediante la explotación de sus recursos naturales, especialmente para la alimentación del ganado aunque no solo. Y, asimismo, el segundo objetivo es intentar realizar algunas aportaciones sobre el uso y gestión de los marjales, además en un sentido diacrónico.

Sin embargo, es necesario advertir que este artículo no ha sido concebido para exponer las conclusiones de una investigación acabada o bastante avanzada. Se trata de una primera aproximación al tema a partir de fuentes escritas posteriores a la conquista cristiana y de diversos análisis morfológicos del paisaje, para elaborar con todo ello algunas hipótesis de trabajo y exponer las perspectivas de investigación que ofrece la zona de estudio. Por lo que respecta a esta última, para mantener una cierta coherencia histórica y geográfica se ha seleccionado el territorio -balad- que en época andalusí dependió en mayor o menor medida de Madīnat Balansiya desde un punto de vista fiscal y jurisdiccional, a pesar de las dificultades para conocer los límites exactos que tuvieron la cora emiral y califal, la primera taifa o el territorio controlado desde esta ciudad por gobernadores durante los periodos almorávide y almohade (figura 1). Por eso no se han considerado las actuales tierras valencianas al sur de las montañas de la Marina (Ŷibāl Balansiya), que siempre pertenecieron a Tudmir y después a Murcia; ni tampoco se estudian las situadas al norte de la cuenca del río Mijares, que parecen haber estado relacionadas con Madīnat Turțūša hasta la conquista cristiana de la ciudad en 1148, cuando pasaron a depender de Valencia. Si bien, a continuación se hará referencia a algún documento de esta última zona.

\section{PASTOS DE MONTAÑA Y PASTOS DE MARJAL}

Las cartas de rendición de las aljamas andalusíes durante la conquista cristiana, en las que se pactaron las condiciones en las que quedaría la población musulmana que no fue expulsada, son una de las primeras fuentes lógicas a las que acudir para encontrar referencias a la ganadería y a la regulación del uso de los pastos en el momento anterior a la propia conquista. De las más antiguas conservadas, la de Cervera (1233) y la de Xivert (1234) se limitan a registrar el dinero por cabeza de ganado que se deberá pagar a las ordenes militares del Hospital y del Temple respec- 
tivamente, que parece ser en realidad el antiguo impuesto islámico del zakāt ahora transformado en renta feudal. No obstante, la carta de Xivert añade que el ganado podrá pastar por toda la tierra yerma dentro del término sin limitación, es decir, por el territorio del antiguo hișn. Y la carta otorgada por el rey Jaime I a los musulmanes de la sierra de Eslida en 1242 dice más o menos lo mismo, especificando además que se trata de una continuación de la tradición andalusí, de manera que son referencias explícitas al libre uso de todas las tierras no cultivadas como pastos durante el período anterior a la conquista. ${ }^{1}$

Sin embargo, son solo algunos ejemplos que confirman lo que ya se sabía a nivel general por fuentes jurídicas sobre la libre disposición comunal de los recursos naturales por parte de todos los musulmanes, sobre todo los pastos, el agua y el fuego en base a un conocido hadìt de Mahoma. Aunque más concretamente se refieren al libre uso de las tierras comunales o harim de las alquerías, de acuerdo con la interpretación de la escuela malikí que, como es bien sabido, es la jurisprudencia que regía en al-Andalus (Trillo, 2004, p. 76). En este sentido, los casos citados de Xivert y Eslida parecen indicar que el libre uso de las tierras yermas para apacentar el ganado perteneciente a las familias de la aljama es un derecho que se ejerce solo dentro del territorio propio de la qarya, o más bien del hiṣn en esta zona septentrional valenciana, pero no más allá. Sin embargo, es discutible si esta limitación territorial de las cartas es una continuidad de la reglamentación andalusí o si, por el contrario, está relacionada con la nueva realidad señorial que regulan estos documentos. En cualquier caso, harim es un término jurídico que solo se aplica a las tierras comunales que son propias de una aljama, a los que no tiene acceso nadie más, pero esto no quiere decir que las comunidades campesinas no puedan disponer también de pastos fuera de su propio territorio.

En Granada se han documentado comunidades de pastos en época nazarí dentro de un mismo distrito (Ramos, 1988; Trillo, 2004, p. 77), y parece claro que había ciertos acuerdos para usar los pastos de los territorios vecinos sin problema, porque antes de la conquista cristiana avía hermandad entre ellos. Si bien es cierto que había igualmente algunas áreas de pasto acotadas en cada alquería, que eran solo para la aljama local y estaban vedadas al ganado de fuera (Malpica, 2013, pp. 24 y 30). Así mismo, también en las cartas de rendición de la zona norte valenciana que estábamos viendo hay algún indicio de ello. Por ejemplo, la carta de Uxó de 1250 -con la que Jaime I confirma a la aljama antiguos derechos tras la guerra de al-Azraq de 1248- aporta una información muy interesante en este sentido, ya que el rey les garantiza

1 La carta de Cervera en Guinot (1991, doc. 7); la carta de Xivert dice: "Verum, bestiarium castro predicti, tam grossum quam minutum, pascat per totum suum terminum in heremo, longe et prope, ad quatuor partes" (Guinot, 1991, doc. 10), y la carta de Eslida: "et ganatum eorum pascat in terminis suis universis, sicut consuevit tempore paganorum” (Guinot, 1991, doc. 45). 
que hajen tots lurs térmens o lurs bestiars, de Uxó, e Nulles, e Almenara, e lo terme de Urmell en la plana, e les vinyes de la alqueria appellada de Carç e Alfàndech, segons que ja eren deputats a ells en temps de moros. E que puxa anar lo lur bestiar en tot lo terme de Xova, segons que a ells era ja legut (Guinot, 1991, doc. 84).

La cláusula es un poco enigmática por el significado de lurs térmens, pero debe tratarse de un problema de traducción porque el documento original de 1250 se redactó en árabe y fue traducido al catalán en 1368, que es la versión que nos ha llegado. Puesto que está relacionado muy claramente con el ganado, es posible que la palabra térmens se refiera a zonas de pasto más o menos acotadas dentro del territorio de los castillos vecinos mencionados, como los que parece haber habido en la Granada nazarí, pero no hay más pistas posteriores que permitan afirmarlo con seguridad. En cualquier caso, es muy evidente que se trata del derecho que tenían los habitantes de Uxó a llevar su ganado a pastar dentro del territorio de estos lugares desde antes de la conquista cristiana, pues se confirma de nuevo mediante una clausula similar, aunque más escueta, en la nueva carta otorgada por el rey en 1277 -relacionada con la segunda guerra de revuelta, iniciada en 1276- donde se dice claramente

que pasquen lurs bestiars per tot lo terme de Uxó e en Nuules e en Almenara [...] e en l'alqueria de Carçe e en Alfandeguella segons que era acostumat en temps de sarrahins (Peñarroja, 2013, p. 220). ${ }^{2}$

La información que proporcionan estas cartas sobre el derecho a usar los pastos de las aljamas vecinas en época andalusí es un indicio importante que permite proponer la posible existencia en Valencia de comunidades de pasto como las mencionadas de Granada. Pero, más allá de la simple noticia de su existencia a través del documento, un análisis del territorio de Uxó y sus distritos vecinos permite entender mucho mejor por qué era necesario compartir esos pastos. El Hịṣn Šūn es un distrito bien conocido desde el punto de vista documental, pues estaba compuesto por diversos hawä’ir o barrios con un carácter gentilicio formando juntos una única aljama (Guichard, 1969). Los límites del castillo andalusí parecen ser aproximadamente los mismos que mantiene en la actualidad el término municipal de la localidad de la

2 La transcripción citada dice "que pusquen lurs bestiars", pero no hay duda de que la lectura correcta debe ser "que pasquen". El sentido de la cláusula queda corroborado también en 1311, cuando Jaime II confirma el derecho a apacentar el ganado de Uxó en los términos de Nules y Almenara, que ahora eran de señorío; y al año siguiente el alcaide del castillo de Uxó exige ante los jurados de Nules que se respete este derecho de la aljama (Peñarroja, 2013, p. 81), demostrándose así que continuaba en vigor a principios del siglo XIV a pesar de las reticencias que la gente de Nules empezaba a mostrar. Por lo que respecta a las alquerías de Castro y Alfondeguilla, que siempre tuvieron una estrecha relación con Uxó, tienen su propia carta de rendición de 1277 , fechada el mismo día y muy similar a la citada de Uxó -aunque en este caso conservada a través de una traducción al aragonés- donde se dice que "atorgamos lures términos pora lures bestiales, por el término d'Alfandeguella e de Castro e por todos lurs logares que costumados eran". Parece, pues, que esta otra aljama también tenía derecho a apacentar su ganado fuera del propio término, aunque no se especifique los lugares exactos por donde podían hacerlo. 
Vall d'Uixó, y este ocupa la mayor parte del valle del río Belcaire o de Uxó, sobre las últimas estribaciones de la sierra de Espadà, pero sin llegar a su desembocadura. De hecho, esta parece ser la clave que explica la existencia del acuerdo por los pastos con las aljamas vecinas y la necesidad de mantener este derecho tras la conquista. Como se puede apreciar en la figura 2, los distritos de Almenara y de Nules se interponían entre Uxó y el mar, impidiendo su acceso a los pastos de la franja litoral. Del mismo modo, aunque el propio término contiene una parte de la sierra, es poco el espacio disponible. Sin embargo, subiendo por el valle y por los barrancos afluentes se llega a los pastos del castillo de Castro, de Alfàndec (actual Alfondeguilla) y de la alquería de Xova (hoy Chóvar). Y estos son, precisamente, los lugares mencionados en las cartas de rendición de 1250 y 1277, seguramente porque están suficientemente cerca para poder volver por la noche a Uxó.

Parece claro que la comunidad de pastos, o al menos el acuerdo de la aljama de Uxó con sus vecinos, se explica por la necesidad de combinar distintos tipos de pasto. A pesar de su cercanía física en la zona litoral, la sierra y el marjal son ecosistemas muy diferentes y, por tanto, producen diversos tipos de plantas adaptadas a su medio natural. En la montaña el pasto es más seco y leñoso por estar compuesto básicamente de garriga, y hay pequeños bosques de carrasco cuyas ramas bajas también pueden ser consumidas. Mientras que el marjal es el dominio del maquis y suele haber plantas halófilas cerca del mar, siendo el pasto más tierno por la humedad. Por eso ambos tipos de pasto se complementan, pues enriquecen la alimentación del ganado no estabulado por la diversidad de especies vegetales que ofrecen -necesaria para un buen desarrollo de los animales-, y garantiza la disponibilidad de alimento a lo largo del año por la posibilidad de mover a los animales por el territorio. De hecho, la combinación de ambos ecosistemas mediterráneos para su uso pecuario parece haber sido la constante en al-Andalus, siempre que esto fuese posible (Malpica et al., 2017; Malpica y García-Contreras, 2019), y continuó haciéndose así tras la conquista cristiana.

La geografía de balad Balasiya es ideal en este sentido, pues no solo presenta áreas montañosas sin alturas demasiado elevadas en el norte, interior y sur del país -las últimas estribaciones del sistema Ibérico y del Prebético-, sino que además presenta una cadena de marjales casi ininterrumpida por toda la costa del golfo de Valencia (figura 1). De hecho, los trabajos realizados en los últimos años por Josep Torró (2016) sobre la apropiación y posterior desecación de estos marjales tras la conquista cristiana -y más especialmente a partir del siglo XIV-, han servido también para demostrar de una forma razonable que en época andalusí no hubo intentos importantes de desecación para usos agrarios. $\mathrm{O}$, al menos, no de una manera lo bastante significativa como para dejar un rastro en el paisaje actual, como sí ocurrió en los casos detectados y estudiados del Pla de Vila, en Eivissa (González Villaescusa y Kirchner, 1997), o los más modestos de Les Arenes, en Tortosa (Virgili, 2010). Más 


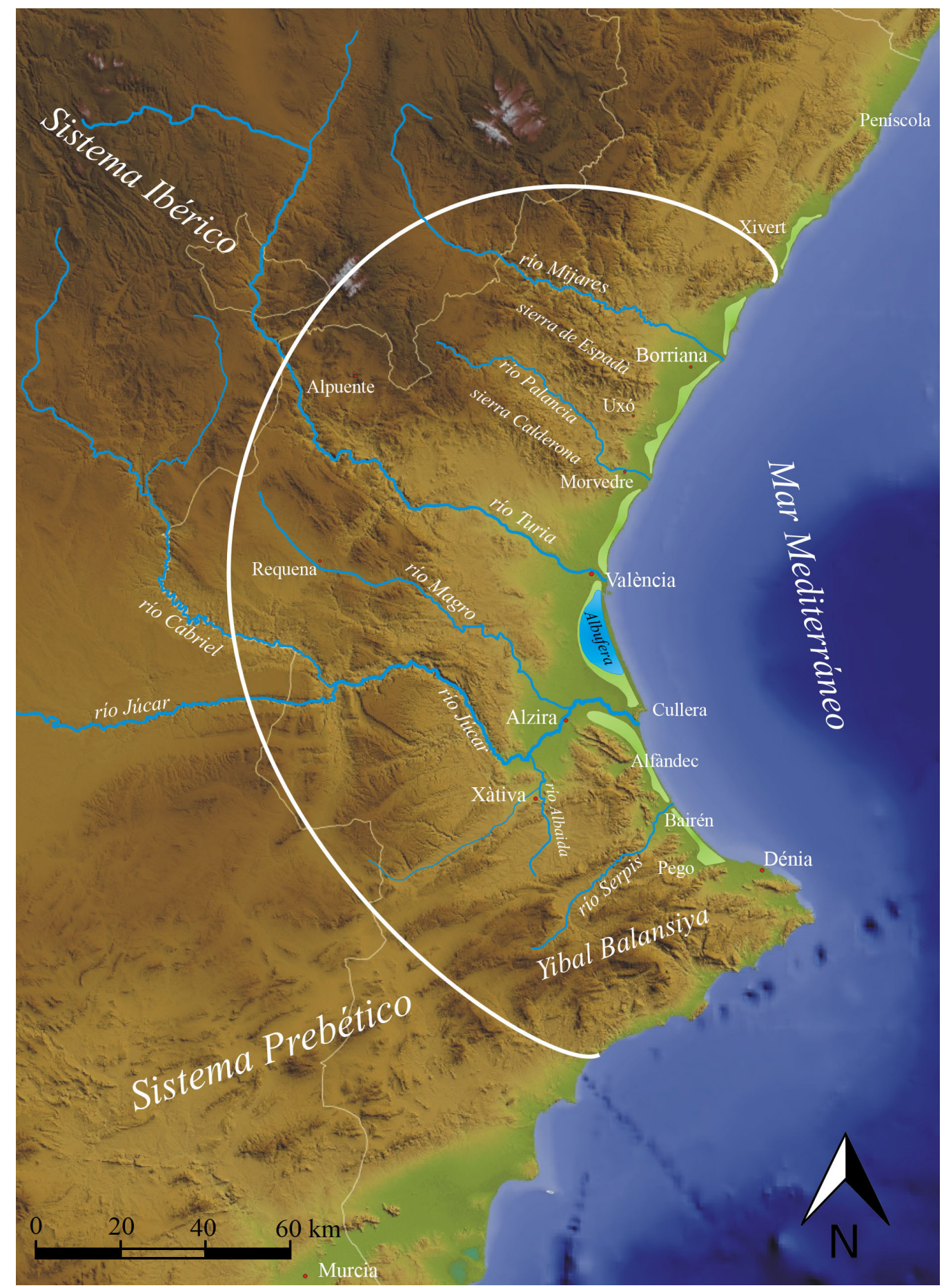

Figura 1: Geografía y extensión de balad Balansiya.

bien al contrario. Como es bien sabido, los marjales fueron zonas dedicadas preferentemente al aprovechamiento de los recursos naturales, como la caza y la pesca, la recolección de plantas con usos industriales y la fabricación de sal, entre otros. Pero, sin duda, fue la alimentación del ganado la forma más habitual de aprovechar sus recursos, sin necesidad de construir grandes infraestructuras de desecación ni realizar dificultosas transformaciones. 


\section{USO Y GESTIÓN DE LOS MARJALES LITORALES COMO PASTOS}

Como hemos ido viendo, es evidente el uso ganadero que se hacía de los marjales, cuya explotación se explica dentro del agroecosistema andalusí más habitual compuesto por cultivos irrigados, de secano y una pequeña cantidad de animales para proporcionar estiércol, leche y ocasionalmente algo de carne a las familias campesinas (Malpica et al, 2017). En este sentido, los pastores de cada aljama -seguramente niños y adolescentes de forma habitual- apacentarían los pequeños rebaños familiares por campos de cereal para aprovechar los rastrojos y por las tierras yermas propias de cada alquería, o de los términos vecinos si existía ese derecho. E irían moviendo a los animales por su territorio combinando los distintos ecosistemas disponibles según la época del año, así como el estado y la abundancia de pasto en cada partida o las necesidades de los animales en cada momento.

El ejemplo mencionado de Uxó es bastante claro en este sentido. A pesar de haber desaparecido ya buena parte de la huerta regada con el agua de la fuente de Sant Josep por el crecimiento urbanístico de la ciudad, aún se identifican de forma razonable en la fotografía aérea de 1957 algunos espacios irrigados andalusíes con una morfología y una superficie similares a los identificados en la Huerta de Valencia (Esquilache, 2018). Estas pequeñas huertas se relacionan muy claramente con los barrios gentilicios que formaban el distrito andalusí de Šūn, que se identifican razonablemente también entre el posterior urbanismo regular de la ciudad que unió los asentamientos a partir del siglo XVIII (figura 2). Por otro lado, existía a continuación un amplio espacio de secano junto al río, aunque en época andalusí no sería tan grande como el área que llegó hasta el siglo XX. Y, finalmente, estaban los marjales de la costa, que, como hemos visto en el apartado anterior, pertenecían a otras aljamas pero había acuerdos para que sus pastos pudiesen ser aprovechados por el ganado de Uxó.

Este esquema se repite a lo largo de la costa valenciana donde están presentes los marjales, tanto en los valles abiertos al mar (Segó, Valldigna, Pego, etc.), como también y más especialmente en las grandes llanuras aluviales, densamente pobladas y con vegas de derivación fluvial (Borriana, Morvedre, Valencia y Gandia). Por mencionar solo algún ejemplo, el caso del marjal de Pego-Oliva ya fue analizado hace años por Josep Torró como paso previo al estudio de su transformación post-conquista, y lo que encontró para época andalusí fue una serie de minúsculos espacios irrigados mediante aceñas situados junto a los barrancos que recorren el valle, intercalados en un área más amplia con cultivos de secano (cereales, olivos, higueras y algarrobos) y una intensa explotación del marjal desde el punto de vista de la ganadería y la recolección. En este caso juncos para la fabricación de esteras y capazos (Torró, 1998, p. 456). Es parecido a lo que se podía encontrar en el valle de Alfàndec -más tarde llamado Valldigna- donde había espacios regados con agua del río Vaca y de diversas fuentes relacionados con las alquerías, espacios de secano 


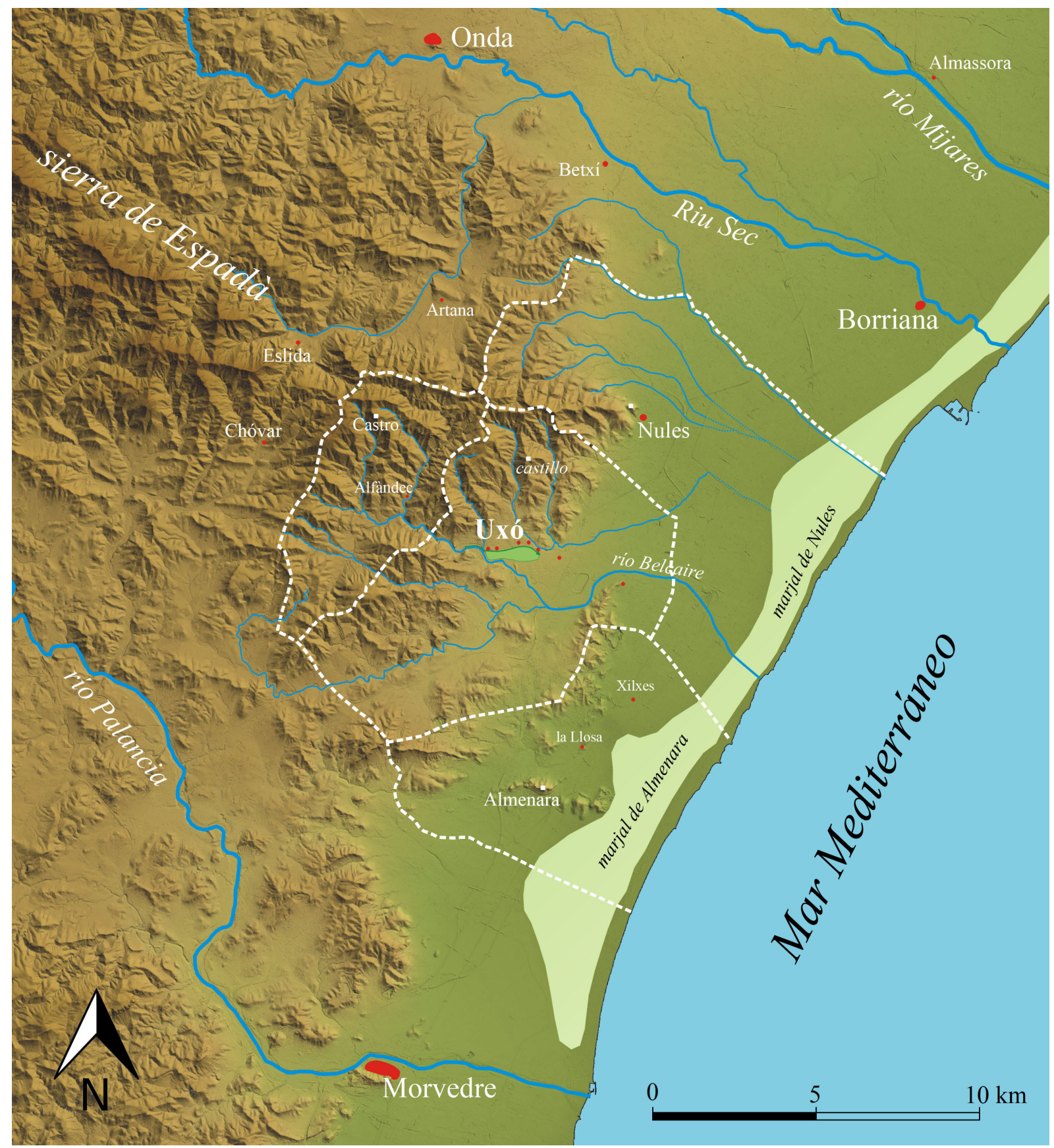

Figura 2: Términos de Uxó, Nules y Almenara.

no tan fáciles de identificar sin estudios más precisos, y una intensa explotación de la sierra y del marjal litoral para usos ganaderos, cinegéticos y recolectores. Unos usos que están bien documentados por Ferran Garcia-Oliver (2003, pp. 39-45) para época bajomedieval, cuando la población mudéjar del valle aún era la mayoritaria, pero que se pueden retrotraer muy fácilmente a época andalusí salvaguardando ciertas imposiciones señoriales.

Sin embargo, más allá del uso obvio y ya conocido de estos espacios naturales como zonas de apacentamiento, caza y recolección en época andalusí, se pueden 
añadir ciertos aspectos más concretos sobre la probable gestión realizada para permitir su mantenimiento y evitar la sobreexplotación. Por ahora no hay muchos indicios claros que indiquen la existencia en al-Andalus de la institución del agdal, que existe entre las comunidades bereberes magrebíes en época contemporánea, y que sirve para abrir y cerrar zonas concretas de pasto al ganado por decisión de la aljama con la intención de garantizar la regeneración de las plantas; aunque por ahora no se puede descartar del todo (Domínguez, 2017). Sin embargo, conocemos otra institución parecida llamada "dula", del árabe dawla, mediante la cual se organizarían los turnos de apacentamiento del ganado entre las familias que formaban la aljama y, de este modo, se evitaba el agotamiento rápido de los pastos. No se sabe a penas nada sobre ella para el período andalusí, pero sabemos de su existencia en época bajomedieval y es probable que se trate de una herencia anterior a la conquista cristiana adaptada a la sociedad feudal, lo que podría ser una prueba de que existían regulaciones en este sentido.

Por otro lado, existen también indicios de otro tipo de gestión del marjal más física, que parece estar relacionada con el aumento de la disponibilidad de los pastos. En primer lugar, si bien es cierto que los marjales proporcionan pastos de buena calidad como se ha apuntado anteriormente, aún hay que tener en cuenta que una característica fundamental de los marjales litorales mediterráneos es que se inundan fácilmente como consecuencia de las lluvias otoñales. Tanto por el aporte directo de agua en superficie a través de los barrancos que desaguan en ellos, como también por el aumento del nivel de la capa freática como consecuencia de la recarga del acuífero por las propias lluvias, aumentando las descargas a la superficie a través de manantiales (Rosselló, 1979). De manera que el encharcamiento del marjal reduce en buena medida la superficie de pastos disponibles, y se hace necesaria alguna clase de acción antrópica cuyo objetivo sea sacar el exceso de agua fuera del marjal para evitar daños en el pasto y aumentar la superficie utilizable. En definitiva, no se trata de desecar el marjal con una finalidad agrícola como en los casos mencionados de Tortosa o Eivissa -aunque en este último caso también se acondicionó un prado para pasto-, y como se hará de forma mayoritaria en los marjales valencianos a partir del siglo XIV en adelante (Torró, 2016), sino que los trabajos se encaminarían a evitar el exceso de agua encharcada para conservar los prados y facilitar el apacentamiento.

En este sentido, de los casos mencionados hasta ahora en este apartado, en Pego llama la atención la existencia de canales de desagüe en el marjal, datados en el siglo $\mathrm{X}$ aproximadamente, que presentan una orientación distinta a la de los azarbes de época cristiana. Hoy en día son indetectables a simple vista porque entre los siglos XV y XVI fueron colmatados artificialmente para hacerlos desaparecer, pero André Bazzana (1992, p. 402) los pudo examinar en los puntos donde se cruzaban con canales actuales -gracias a unos trabajos de saneamiento- y dató su construcción en época califal por la cerámica localizada en el fondo, que parece corresponder al 
momento inicial. Josep Torró (1998, p. 456) ya se preguntó en su momento por la finalidad de estos canales de desagüe, y llegó a la conclusión de que podrían ser un intento fallido de bonificación del marjal o, quizá, que tuviesen la finalidad de evacuar el exceso de agua para estabilizar el borde del área pantanosa y evitar el encharcamiento con una probable finalidad ganadera y para facilitar la recolección de juncos. Actualmente sigue siendo imposible decantarse por una opción u otra, porque no se han hecho estudios específicos al respecto, pero la segunda opción parece bastante más factible porque de no haber tenido un uso durante un largo periodo de tiempo no hubiesen podido existir hasta el siglo $\mathrm{XV}$, cuando se inició su colmatación.

De igual modo, también en Alfàndec/Valldigna hay algunos indicios que apuntan a la existencia de infraestructuras de desagüe de época andalusí. Cuando en el siglo XV el monasterio de Santa Maria de Valldigna, con el beneplácito y ayuda de la aljama mudéjar, intentó construir una acequia en el marjal para extender el cultivo de arroz, la vecina villa de Cullera presentó quejas al rey por los problemas que ello ocasionaría a sus pastos, de manera que el proyecto tuvo que ser abandonado por el momento. Lo interesante es que entre los argumentos esgrimidos por los jurados de Cullera estaba el hecho de que los desagües del marjal de Valldigna, que era supuestamente de temps de sarrahins, siempre se habían dirigido hacia el sur, hasta el estany de Xeraco, que es su salida natural hacia el mar (Garcia-Oliver, 2003, p. 42). En efecto, la desembocadura del río Vaca se realiza aún actualmente mediante un canal artificial que se dirige hacia el sureste, y la mayoría de los azarbes de la zona presentan la misma orientación. Evidentemente, ni todos esos canales son de época andalusí, ni una frase recurrente en la documentación, que fue escrita en el siglo $\mathrm{XV}$, es una prueba sobre el origen cronológico de los desagües del marjal, pero es un indicio interesante a considerar de cara a futuras investigaciones.

Finalmente, cabe mencionar un caso mejor estudiado, que es el del marjal norte de la Albufera. El análisis morfológico intensivo de los diversos sistemas de irrigación de la Huerta de Valencia (Esquilache, 2018) ha permitido identificar los espacios irrigados de época andalusí de las acequias de Rovella y Favara, y estos estaban situados en la llanura aluvial, fuera del marjal pero muy cerca de su perímetro. No así los canales de conducción del agua, que no terminan en los espacios irrigados sino que se alargan a través del marjal para desaguar en la Albufera (figura 3), evitando de este modo que toda el agua sobrante del riego se esparza por el área pantanosa y la encharque. Lo más interesante de este caso, no obstante, es que la identificación de las diversas etapas de construcción del sistema de irrigación, y por tanto de sus desagües, también permite aportar indicios de cronología a la acción antrópica sobre el propio marjal, y a su uso como zona de apacentamiento.

Durante la primera etapa de construcción del sistema de la Séquia de Favara-que debe relacionarse muy probablemente con grupos campesinos que formaban parte 
de la confederación tribal Hawwāra que le da nombre- esta acequia solo regaba las huertas de las alquerías de Altell, Malilla i Patraix, por lo que el canal principal terminaba antes del barranco de la Rambleta, que es el desagüe natural a donde seguramente iría a parar en origen el agua sobrante (figura 3). Sin embargo, el cauce de la Rambleta, que está muy bien definido en la llanura aluvial cultivada, se pierde al entrar en el marjal porque las avenidas nunca han llegado a excavarlo, de manera que el agua sobrante desaguada por la acequia de Favara debía esparcirse como una lámina superficial provocando el encharcamiento constante y haciendo inservible el marjal para el apacentamiento. Esto es lo que debió obligar a los primeros usuarios del sistema a alargar el canal de desagüe artificial a través del marjal, por dentro del cauce indefinido de la Rambleta, para poder conducir el agua hasta la Albufera, desaguando por la punta del Brosquil (figura 3). Este es el azarbe que en la docu-

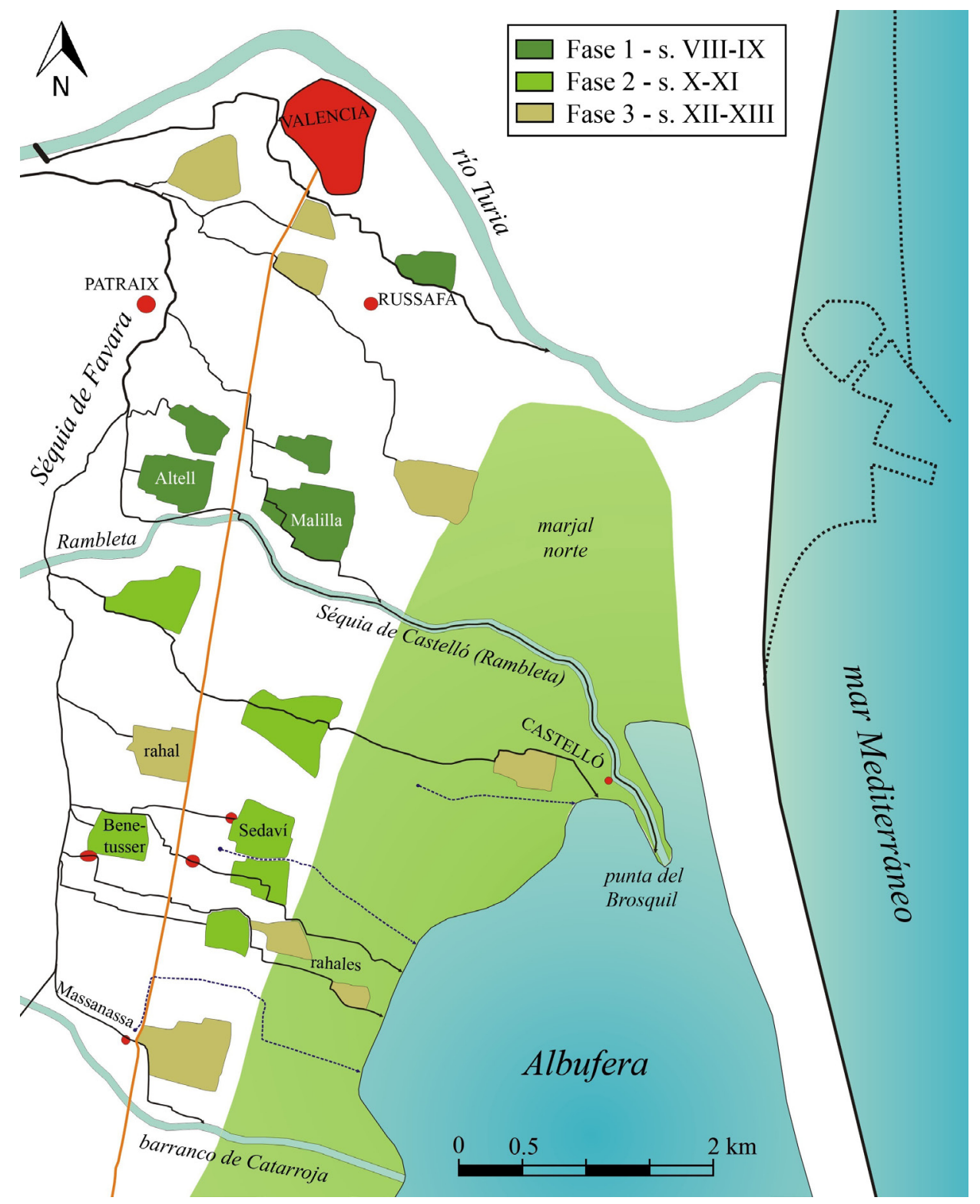

Figura 3: Acequia de Favara en época andalusí y marjal norte de la Albufera. 
mentación bajomedieval aparece con el nombre de Séquia de Castelló, y desde el siglo XVI como Séquia del Rei (Torró y Esquilache, 2018).

Se trata de otro ejemplo, pues, de la presencia de infraestructuras hidráulicas en el marjal para evitar su encharcamiento. En este caso para evitar problemas derivados de los sobrantes de la irrigación. Además, se trata de una actuación bastante antigua dentro del período andalusí, pues la primera fase de construcción del sistema de irrigación de Favara que generó el problema en el marjal pertenece con bastante probabilidad a los primeros siglos de existencia de al-Andalus (Esquilache, 2018), por lo que el canal de desagüe de Castelló se tuvo que construir poco después del sistema. A no ser que este formase ya parte del diseño inicial, y el agua nunca llegase a encharcar el marjal porque ya se había previsto desde el principio que esto no sucediese, pero es muy difícil precisarlo. A partir del siglo $\mathrm{X}$ en adelante, cuando se amplió el sistema de irrigación en diversas fases para añadir más espacios irrigados de alquerías y de rahales, se siguió construyendo el mismo tipo de desagües para conducir el agua sobrante hasta la laguna (figura 3). Lo que permite deducir que el marjal situado junto a la zona de cultivo mantuvo el mismo uso pecuario de forma continua durante todo el período andalusí, pues siempre se buscó una misma solución al problema de los sobrantes de la irrigación.

Además, el crecimiento y evolución del sistema hidráulico a lo largo de los siglos permite proponer también cambios en la gestión o la posesión del suelo a lo largo del período andalusí. Se puede apreciar como durante la fase más antigua, claramente tribal por la relación de la acequia con los Hawwāra, el marjal parece estar a disposición del ganado de los grupos campesinos que cultivaban estas huertas de alquería. Sin embargo, en su fase final, previa a la conquista cristiana, cuando las tribus hacía tiempo que no existían como instituciones políticas, este marjal al norte de la Albufera estaba lleno de rahales. No es necesario entrar ahora en el análisis sobre la naturaleza de los rahales, sobradamente conocido, y basta con recordar que se trata de concesiones de tierras muertas para su explotación agropecuaria, realizadas por el Estado mayoritariamente a favor de sus agentes y de particulares a su servicio (Guichard, 2001, pp. 518-522). En esta zona concreta dentro del marjal se han podido identificar algunos rahales gracias a su espacio irrigado, como el Rahal Abinsancho o el Rahal Abingatir (Esquilache, 2018), pero muy probablemente habría más que por ahora no se pueden localizar por no tener una huerta y estar dedicados solamente a la ganadería. No en vano, entre los inicios de la sociedad andalusí y su final, previo a la conquista cristiana, los cambios habían sido bastante significativos en este sentido, a pesar de mantenerse siempre el uso ganadero del marjal. Así, parece que en algún momento se produjo una privatización parcial de las tierras comunales, aunque se trata de un tema que necesitará de más estudios que permitan identificar rahales ganaderos; si esto es posible con las metodologías actuales. 


\section{LOS MARJALES LITORALES COMO EXTREMALES TRASHUMANTES: EL CASO DE LA RIBERA BAIXA DEL RÍO JÚCAR}

Hasta ahora hemos visto que el uso pecuario de los marjales litorales parece estar relacionado con comunidades rurales que vivían en sus alrededores, combinando en todos los casos agricultura y ganadería independientemente de la importancia que cada una de ellas tuviese respecto a la otra, que por ahora es muy difícil de precisar. De hecho, por el momento el registro arqueozoológico parece mostrar que este fue el sistema mayoritario de cría de ganado en al-Andalus, caracterizado por la combinación de rebaños familiares de pocas cabezas y una agricultura intensiva (García y Moreno, 2018, p. 34). Sin embargo, podría no haber sido así siempre ni en todas partes, y que algunos marjales de la costa hubiesen sido, también, el destino invernal de algunos rebaños foráneos. Lo que nos lleva a plantear la posibilidad de que hubiese habido rebaños trashumantes en al-Andalus, o quizá transterminantes de más corto recorrido.

Desde luego, parece que en la Granada nazarí había transtermitancia entre la costa y la Alpujarra o hasta Sierra Nevada. Y también hay ciertos indicios de haber habido trashumancia andalusí con rebaños de origen más lejano, hacia el norte, que tras la conquista cristiana del Valle del Guadalquivir y la estabilización de la frontera con el emirato nazarí continuó haciéndose con rebaños de ganaderos cristianos (Malpica, 2013; Malpica et al., 2017). Incluso en la zona septentrional del País Valenciano hay indicios de haber habido trashumancia en este mismo sentido, a partir de la conquista de Tortosa y del Bajo Aragón, con rebaños de cristianos entrando en territorio islámico en invierno, aunque ello no sea una prueba de la existencia de una trashumancia andalusí anterior (Royo, 2020, p. 16). Así pues, nada impide suponer que los marjales de la costa valenciana (figura 1) hayan podido recibir rebaños transterminantes compartiendo los pastos con el ganado local, aunque de momento no se pueda saber si fue así o no. El caso que hemos estado viendo sobre el derecho de Uxó a usar los pastos del marjal de Almenara y Nules podría ser extensible a toda la sierra de Espadà, aunque no haya pruebas documentales y sea más inverosímil por la sobreexplotación del marjal que ello podría haber supuesto. En cualquier caso, es una posibilidad para ser estudiada con más detalle en el futuro, del mismo modo que en el caso del marjal de Pego-Oliva, tras el cual hay una serie de valles montañosos con una clara dedicación ganadera del territorio en época andalusí.

Pero es cierto que no todos los espacios de marjal tendrían la suficiente capacidad para soportar ganado local y foráneo, como consecuencia de su reducida extensión total y del encharcamiento ocasional. Este sería el caso de las grandes llanuras aluviales, como por ejemplo la Huerta de Valencia o la Plana de Borriana, donde los marjales eran una estrecha franja litoral a causa del poder de aterramiento natural de los ríos Turia y Mijares. Además, estas llanuras tenían una alta densidad de población, lo que conlleva tener que soportar una mayor cantidad de animales locales que 
otros marjales. Tanto los rebaños de las familias campesinas como animales de trabajo y, también, los destinados a carne para las medinas. Sin embargo, hay marjales más extensos y con el poblamiento más disperso, que sin duda tenían la capacidad de alimentar a un mayor número de cabezas.

Este podría ser el caso de la Ribera Baixa, en la desembocadura del río Júcar, que estaba compuesta por un extenso marjal situado al sur de la Albufera y también por el marjal de Cullera-Corbera, formando ambos una clara unidad a pesar de estar separados por el río y sus depósitos de relleno. Se trata de una zona distinta a los espacios de marjal que hemos visto en el apartado anterior, de manera que la podemos ver ahora con más detalle para saber hasta qué punto existen indicios suficientes para considerar si en época andalusí fue o no un extremal de invierno trashumante. Para empezar, se debe señalar que antes de la conquista cristiana no hubo en esta zona ningún sistema de irrigación derivado del Júcar, a pesar de ser la Ribera una llanura aluvial igual a las de Valencia o Castelló. Sabemos que había sistemas fluviales un poco más arriba de los marjales, en el término de Alzira, que se alimentaban con agua de tres ríos afluentes, pues el Júcar era demasiado caudaloso para los azudes medievales y, por eso, en la parte baja de la desembocadura, donde no hay afluentes, no hubo huertas fluviales hasta bien entrado el siglo XV (Furió y Martínez, 2006).

Sin embargo, como se puede observar en la figura 4, en época andalusí la Ribera Baixa era una zona densamente poblada gracias a una tupida red de pequeñas alquerías que se organizaban mediante dos distritos fiscales, los hușūn de Cullera y Corbera. En el mapa aparecen más de una treintena de asentamientos que sabemos que existían en el momento de la conquista cristiana, aunque había algunos pocos más que conocemos a través de menciones esporádicas en documentación bajomedieval que por ahora son ilocalizables (Cortés et al., 1981). Es posible, incluso, que hubiese alguna otra alquería de la que no ha quedado rastro, ni documental ni toponímico. En cualquier caso, como se puede ver en el mapa, todas las localizadas se encontraban situadas alrededor del marjal, envolviéndolo, lo que permite suponer que este ecosistema natural tendría una gran importancia en su economía.

Puesto que no hay huertas fluviales, los cultivos irrigados siempre fueron escasos, pero parece que no del todo inexistentes. A los pies de la sierra de Corbera, por ejemplo, en una estrecha franja de abanicos aluviales formados por pequeños barrancos que bajan de la sierra hasta el marjal, había diversas alquerías cuyos espacios de cultivo de época andalusí son difíciles de identificar. Existe alguna noticia referida a espacios irrigados de muy pocas hectáreas (Vercher, 2006) y, ciertamente, hay algunas fuentes repartidas por la sierra que pueden haber sido utilizadas para alimentar sistemas de irrigación junto a los barrancos. Sería necesario realizar un estudio mucho más pormenorizado mediante prospección para poder localizarlos, porque las transformaciones realizadas en el siglo XX para construir huertos de na- 
ranjos no permiten una identificación clara, pero para el objetivo de este artículo es suficiente con retener ahora que, seguramente, había algunos sistemas irrigados de pocas hectáreas y, en cualquier caso, es obvio que hubo cultivos de secano en los mencionados abanicos aluviales.

Hacia el noroeste, en las alquerías de Benicull y Montcada había algunos ullals o fuentes de agua subterránea que alimentaban pequeños sistemas (Vercher, 2006). Y, si pasamos al lado norte del río Júcar, los manantiales de Segairent y la Tancadeta eran el origen de una acequia que llevaba el agua a diversos espacios de cultivo en las alquerías de Albalat, Campanar, Segairent, Saucelles, Alborx y Sueca. Este fue, probablemente, el sistema de riego más importante de toda la Ribera Baixa en época andalusí (Furió y Martínez, 2006). No obstante, las numerosas acequias construidas en época moderna y contemporánea a partir de agua del río y otros manantiales complican la identificación y delimitación del sistema andalusí sin un análisis morfológico en profundidad de toda la zona. Por eso, de momento es suficiente con saber que existía, aun siendo de escasa entidad comparado con un sistema de irrigación fluvial.

Finalmente, por lo que respecta a las motas entre las que se encaja el río Júcar, en el tramo de Riola a Cullera también había alquerías aprovechando los depósitos de tierra durante las crecidas (figura 4). Un poblamiento muy parecido al sistema de alquerías existente junto al cauce del río Ebro, en su tramo final hacia el delta (Virgili, 2010). En este caso sabemos que hubo algún pequeño espacio irrigado a través de grandes norias que elevaban el agua desde el río, de las que se tiene constancia por los permisos de reconstrucción que se dieron a principios del siglo XIV, de manera que ya existirían antes de la conquista. De hecho, en el Llibre del Repartiment aparece mencionado un huerto situado entre Fortaleny i Matada (Ferrando, 1979, reg. 2317).

Así pues, como podemos ver, en época andalusí la Ribera Baixa era una gran zona en la desembocadura del río Júcar que combinaba grandes áreas de marjal con pequeñas áreas de cultivo. Tanto de secano como de regadío, a pesar de contar con una capacidad limitada de agua aprovechable en superficie -al menos en comparación con las vegas fluviales-, pues existían diversos espacios irrigados de los que no conocemos cual era su tamaño pero todo indica que serían bastante pequeños. Incluso parece seguro que no todas las alquerías contarían con una huerta. Sin embargo, el número de asentamientos era importante y, en consecuencia, habría una alta densidad de población, de lo que parece deducirse que en esta zona los cultivos irrigados no eran la parte más importante de su agrosistema. Al contrario, todo parece girar preferentemente sobre la explotación del marjal; esto es, sobre la caza, la pesca, la producción de sal y la recolección, pero también, y especialmente, sobre la ganadería. De hecho, recuerda mucho al sistema de poblamiento y producción agropecuaria andalusí de la desembocadura del río Segura, con minúsculos espacios 


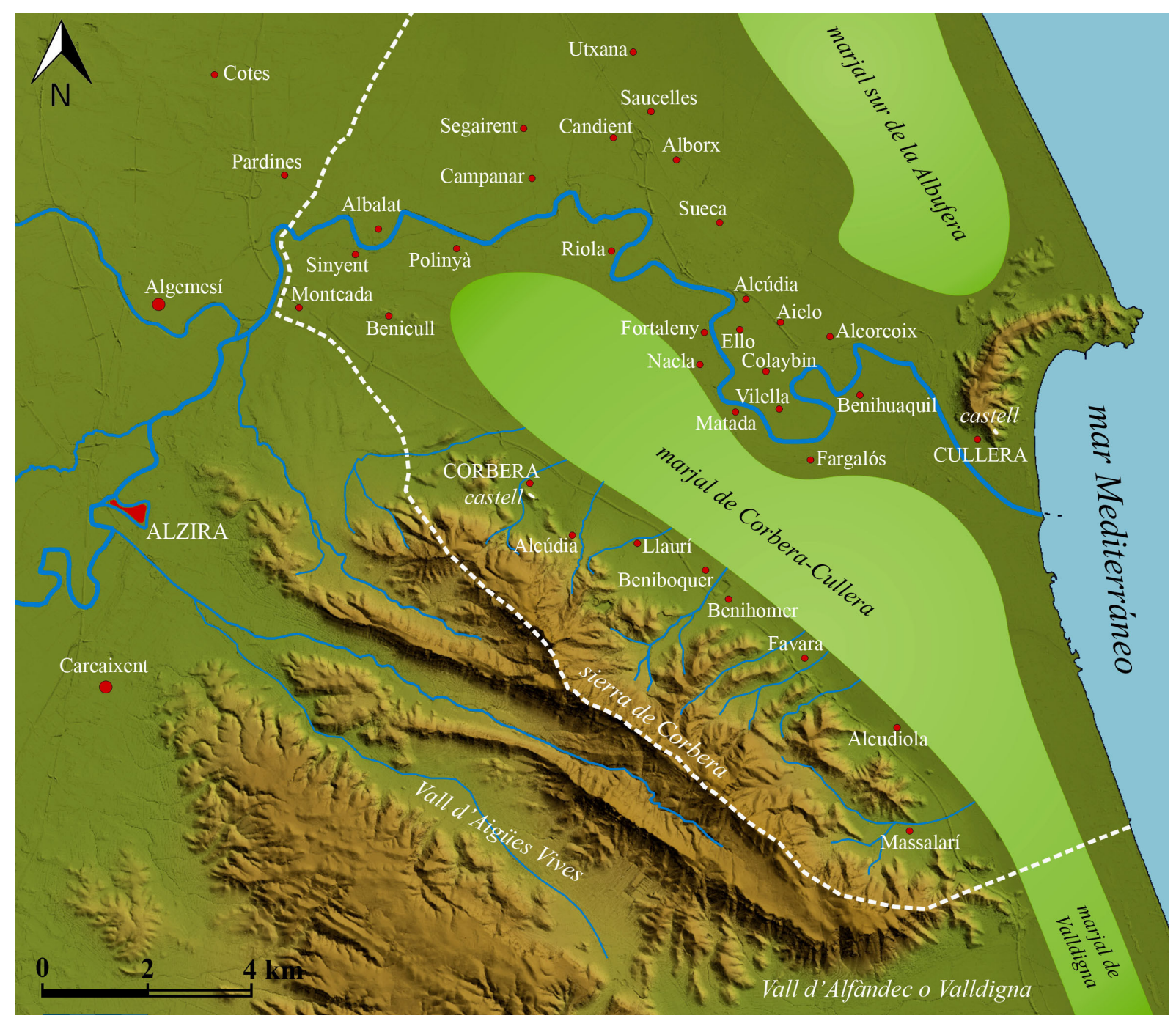

Figura 4: La Ribera Baixa del Júcar en época andalusí.

irrigados entre las áreas de secano y un aprovechamiento muy intenso del marjal (Gutiérrez, 1995; Parra, 2019).

Este tipo de áreas pantanosas extensas han sido consideradas tradicionalmente como marginales, porque se tenía en mente la preminencia de la agricultura irrigada de las grandes vegas fluviales. Sin embargo, esta perspectiva está empezando a cambiar, y ahora se entiende que los marjales se incluyen en un tipo muy concreto de agrosistema andalusí adaptado a este medio natural (Malpica y García-Contreras, 2019). Un medio presente, de hecho, por todo el Mediterráneo, que ha sido bien aprovechado por diversas sociedades (Horden y Purcell, 2000). Sin embargo, no podemos contentarnos solo con esta explicación, pues es necesario intentar entender cómo evolucionaron estos espacios a lo largo del tiempo aunque no se hayan realizado excavaciones que aporten dataciones absolutas. La reconstrucción de la Ribera Baixa en época andalusí realizada hasta aquí es una imagen estática, del momento en el que su evolución histórica queda interrumpida por la conquista y fijada en el 
paisaje. Pero no debemos suponer que, necesariamente, la explotación del marjal se realizó siempre del mismo modo entre los siglos VIII y XIII, pues los cambios sociales influyen también en el uso de los recursos como hemos visto en el marjal al norte de la Albufera.

Resulta obvio que esta zona requiere un exhaustivo estudio arqueológico para poder conocer mejor su evolución pero, para plantear ahora las primeras hipótesis, la toponimia puede aportarnos pistas importantes. Ya hace bastante tiempo que Pierre Guichard (1980) llamó la atención sobre el nombre de cuatro de las alquerías situadas en la Ribera Baixa: las de Favara (< Hawwāra), Llaurí (< al-Hawwāriyyīn), Benihuaquil (< Banī Wakīl) y Fargalós (< Fargalūš). Con su habitual prudencia, Guichard proponía que esta toponimia debía de estar relacionada, muy probablemente, con los nombres de un personaje que en 829 participó en la conquista islámica de la isla de Sicilia, llamado Aṣbag ibn Wakīl al-Hawwārī, más conocido como Fargalūšs, que probablemente era originario de esta zona. Lo que dataría estos asentamientos, como mínimo, en la primera mitad del siglo IX, aunque es posible que fuesen más antiguos. Además, relaciona este marjal de la Ribera Baixa con el medio tribal y con la confederación Hawwāra, como en el del norte de la Albufera. De hecho, aunque no menciona específicamente a esta tribu ni a ninguna otra concreta, es bien sabido que el geógrafo oriental al-Ya'qubi (muerto en 897/8) atribuye a las tribus bereberes (qaba’il al-barbar) asentadas en esta región la posesión de un gran río llamado alŠuqr, es decir, el Júcar (Guichard, 1969). Esto quiere decir que los Hawwāra no eran probablemente los únicos que estaban presentes, pero sí parecen ser la tribu preeminente en esta región, pues controlaban el marjal al norte de la Albufera gracias a la acequia de Favara y tenían también asentamientos en el marjal del sur. Si no es que lo controlaban todo, como parece lógico suponer.

Sin embargo, lo más interesante de todo esto es que las mismas tribus beréberes que poseían y/o controlaban en el siglo IX las desembocaduras del Turia y del Júcar, entre ellos fracciones de los Hawwāra como grupos destacados, controlaban también sus cabeceras. Es decir, poseían la serranía de Cuenca y la sierra de Albarracín, la parte más al sureste del sistema Ibérico donde nacen los dos ríos mencionados, en la küra de Santaver. La documentación indica que aquella fue también una zona de asentamiento de tribus bereberes, entre los que inicialmente parecen haber sido los Madyūna los preminentes. Los Hawwāra solo se hicieron con el control tribal de la kūra a principios del siglo IX, a través del linaje de los Banū Zannūn, pero sabemos que estaban presentes en la región desde tiempos de la conquista (Guichard, 1969). Por su parte, también eran Hawwāra los Banū Razīn que dan nombre a Albarracín, en la sierra donde nace el río Turia (Bosch, 1959).

A partir de aquí se podrían añadir más datos sobre la presencia de tribus beréberes en general, y fracciones Hawwāra en particular, en las montañas al sureste de Santaver. Y, sin duda, es necesario plantear un programa de investigación arqueo- 
lógica dentro del triángulo formado por Teruel, Albarracín y Cuenca que estudie el poblamiento y las actividades económicas andalusíes de esta zona, más allá de estudios etnográficos que presuponen continuidades de muy larga duración (AlmagroGorbea, 2001). Pero, por ahora, es suficiente con corroborar su presencia para poder plantear preguntas respecto al tema que nos ocupa. ¿Por qué las mismas tribus, especialmente fracciones Hawwāra, controlaban la cabecera y la desembocadura del Turia y del Júcar? La respuesta lógica, que debe ser considerada una hipótesis de trabajo a partir de ahora, es que con ello su intención era controlar los pastos de las montañas del interior y los marjales de la costa. Pero esto solo tiene sentido si se admite la posibilidad de que estos grupos tuviesen una estrategia económica basada en la ganadería trashumante, y que ambos espacios fueran sus extremales, es decir, sus pastos de verano e invierno respectivamente. ${ }^{3}$

Desde luego, el sistema Ibérico es una zona de gran actividad ganadera donde las áreas de cultivo parecen haber sido bastante escasas. Además, estas montañas han estado relacionadas históricamente con la costa valenciana mediante rutas trashumantes, pues la propia geografía induce a su conexión física. Todas las vías pecuarias de largo recorrido que unen estos dos puntos -desde época bajomedieval al menos-, y que han llegado a la actualidad, presentan la misma orientación noroeste-sureste, siguiendo tres rutas básicas. ${ }^{4}$ Desde la serranía de Cuenca la ruta tradicional llega a la costa valenciana a través del valle del río Magro, pasando por la planicie de Requena y la hoya de Buñol hasta la Ribera Alta del Júcar. De hecho, la llamada Cañada Real del Reino de Valencia, que partía desde Cuenca, era la única de las que formaban parte de la Mesta castellana que salía de su reino y penetraba en la Corona de Aragón, para aprovechar estos pastos litorales. Si bien, en época bajomedieval los ganaderos conquenses solían preferir ir a Murcia, por estar menos poblada y tener menor presión, a pesar de estar más lejos.

Desde Albarracín y toda su sierra la ruta al litoral es más recta, aunque también más accidentada, penetrando en el actual País Valenciano a través de Ademuz y de Alpuente, para bajar después por el valle del Turia. Lugar donde se encuentra, por cierto, la localidad de Benissanó, un asentamiento de los mismos Banū Zannūn de

3 Hay un estudio arqueozoológico basado en el basurero del castillo de Albarracín que defiende la existencia de una producción ganadera local por las pautas estacionales de sacrificio de los animales (Moreno, 2004). Sin embargo, estos resultados no pueden ser considerados concluyentes. En primer lugar porque los restos estudiados indican las pautas de consumo del castillo, no las de producción de las comunidades campesinas. De hecho, aunque haya trashumancia no todo el ganado se va, porque no se puede desabastecer de carne y leche la sierra de Albarracín, de manera que los animales que se quedan son los que se consumen y acaban en el basurero. Por otro lado, el registro arqueológico del castillo empieza a mediados del siglo XI, cuando los Banū Razīn ya se comportan como élites estatales de su taifa, y no cubre el periodo anterior, durante la fase plenamente tribal, que sería la más interesante para el tema que nos ocupa.

4 Información basada en el Catálogo de Vías Pecuarias que elabora la Generalitat Valenciana a través de la Conselleria de Territori i Medi Ambient. 


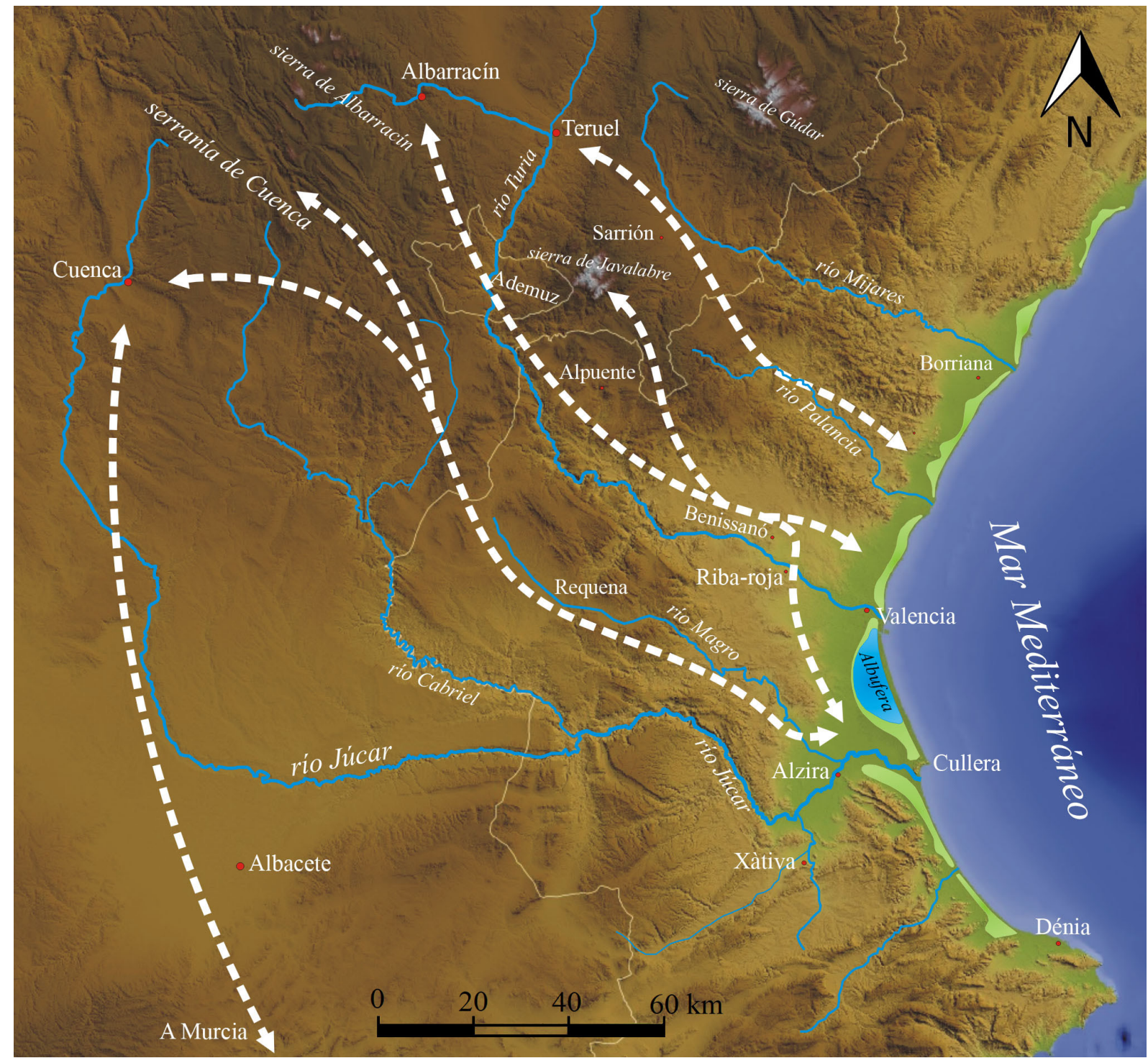

Figura 5: Corredores naturales entre las serranías ibéricas y la costa valenciana.

la confederación Hawwāra que en época emiral dominarían la kūra de Santaver. Y, finalmente, la ruta más al norte es la que, desde Teruel y sus alrededores, bajaba a la costa valenciana por el valle del río Palancia (figura 5). Así pues, las rutas son claras, porque se trata de tres corredores naturales que se han venido utilizando desde siempre. Aunque esto no quiere decir que las vías pecuarias que han llegado a la actualidad sean exactamente las mismas ya desde época andalusí, o más atrás aún en el tiempo, porque el trazado de cañadas y azagadores puede cambiar para adaptarse a las necesidades de cada momento. De hecho, la red de caminos se hace más densa cuando el movimiento aumenta, como pasó en época bajomedieval y moderna, pero, aun así, las rutas básicas de movimiento de ganado no pueden cambiar demasiado porque son las únicas posibles siguiendo la topografía, los pastos, el acceso al agua, a la sal, etc. 
En cualquier caso, si la trashumancia entre estos dos puntos existió, en principio no parece que se trate de tribus nómadas viviendo medio año en las montañas y el otro medio en la costa. Es dudoso -aunque no imposible- que hubiese tribus de este tipo en al-Andalus (Ortega, 2018, pp. 214-222), por lo que es mucho más lógico que se tratase de familias amplias diferentes, asentadas habitualmente en un extremo o en el otro de las rutas, compartiendo sus pastos de verano y de invierno a través de pactos tribales. De hecho, es necesario recordar que una tribu no es más que una asociación política y económica entre grupos familiares basada en la ideología del parentesco -que puede ser real, o más habitualmente ficticio-, que sirve entre otras muchas cosas para compartir pastos. Por tanto, aunque nos movamos por ahora en el terreno de las hipótesis, parece más probable que los rebaños se trasladasen en cada estación del año acompañados de un grupo de pastores, y no por familias extensas al completo.

Por otro lado, es necesario preguntarse qué objetivo tendría esta trashumancia, que no puede ser el mismo que el de las comunidades campesinas que combinaban el cultivo con rebaños domésticos para diversificar estrategias económicas. ¿Eran rebaños para carne o para lana con una finalidad textil? Además, ¿que tipo de intercambios con los productores de cereal de las grandes vegas irrigadas se producían cuando el ganado llegaba a la costa para pasar el invierno? Son preguntas que, si se confirma la hipótesis de la trashumancia, la investigación tendrá que ir resolviendo, pues son básicas para entender el funcionamiento del sistema productivo en los primeros siglos de al-Andalus.

Además, el siguiente paso deberá ser intentar identificar y datar sus fases, si las hubo, ya que resulta lógico y probable que este sistema de ganadería trashumante tribal tuviese su origen poco después de la conquista islámica de la península, y no hay razón para pensar que el sometimiento califal de las tribus bereberes de estas regiones durante la primera mitad del siglo $\mathrm{X}-\mathrm{y}$ su consecuente desactivación política- interrumpiese el movimiento de rebaños. Más bien al contrario, pues mover ganado permite contabilizar mucho más fácilmente el número de cabezas a su paso por ciertos lugares concretos y, por tanto, fiscalizar su posesión. Por otro lado, sería muy necesario preguntarse también por el papel de las ciudades a partir de los siglos X y XI en adelante, especialmente de Madīnat Balansiya, e intentar saber si la producción local campesina pudo abastecer la demanda creciente de carne y de lana o bien si la trashumancia suplió esta necesidad.

En cualquier caso, el problema llegaría durante la segunda mitad del siglo XII, cuando Ibn Mardanish entregó Albarracín a la familia Azagra, en 1170, y se produjo la conquista cristiana de Teruel (1171) y de Cuenca (1177). Muy probablemente, en ese momento los pactos tribales por los pastos de los extremales ya habrían desaparecido desde hacía mucho tiempo y, si se había mantenido la trashumancia entre los dos puntos señalados, esta se realizaría con el pago de impuestos por el 
uso de esos pastos, que jurídicamente serían tierras comunales pero que gestionaría el Estado. En la Granada nazarí, de nuevo, la trashumancia y la transtermitancia ya funcionaban así, pues, si bien no está demasiado clara aún la naturaleza del talbix, parece ser que era el impuesto que se pagaba a los quwwād de los castillos por el uso de los pastos al paso de los rebaños (Malpica, 2013). Sin embargo, con la pérdida de los pastos de verano por la conquista cristiana, el sistema trashumante habría dejado de tener sentido y, necesariamente, debió readaptarse. Es probablemente en este momento cuando se construyen en la Ribera Baixa la mayoría de los sistemas de irrigación mencionados anteriormente. Aunque esto, una vez más, solo se podrá certificar a través de análisis arqueológicos precisos, pues el análisis del paisaje es limitado. Sin embargo, tanto si la hipótesis de la trashumancia se confirma como si se descarta, de todo ello se podrán extraer unas conclusiones bastante importantes sobre el funcionamiento y la evolución de la ganadería andalusí a lo largo del tiempo.

\section{CONCLUSIONES}

La ganadería andalusí es un tema complicado de estudiar por la falta evidente de fuentes, incluyendo la dificultad y el coste de la recogida de datos arqueológicos. Sin embargo, la documentación escrita puede aportar pequeños indicios, que por si solos no tienen demasiado valor por la escueta información que proporcionan pero combinados con estudios del paisaje pueden ser más explícitos. De hecho, aunque es evidente que la arqueología de excavación, y concretamente la arqueozoología, es la metodología clave para el estudio de la ganadería andalusí, parece que la arqueología del paisaje aún puede aportar muchas cosas. Sobre todo durante las primeras fases de investigación, cuando se elaboran las hipótesis de trabajo. Esta era la intención del presente artículo, y por eso sería redundante incidir ahora sobre ello, pero sí resulta pertinente destacar de nuevo la necesidad de cronología.

Los estudios sobre la ganadería andalusí deben ser siempre diacrónicos, o al menos presentar esta perspectiva, pues su funcionamiento no pudo ser exactamente el mismo durante todo el período andalusí porque la evolución de la sociedad debió influir en ella. No puede ser igual el ambiente probablemente tribal de la sociedad andalusí durante sus primeros siglos de existencia -cuando parecen ser las propias tribus las que controlan sus pastos y llegan a acuerdos con otros grupos para usarlos y regularlos, al menos entre los bereberes-, que durante la posterior superposición del Estado sobre las comunidades campesinas a partir del Califato de Córdoba en adelante, que es cuando se consigue desactivar a las tribus como instituciones políticas y comienza más claramente la articulación de lo que se ha convenido en denominar formación tributaria-mercantil.

En este sentido, el caso de los marjales norte y sur de la Albufera de Valencia parece ser manifiestamente claro, porque durante los primeros siglos de existencia 
de al-Andalus deben haber estado, muy probablemente, en manos de la confederación tribal Hawwāra. Sin embargo, en los momentos previos a la conquista cristiana parece que se habría producido una privatización del espacio comunal de apacentamiento mediante la concesión de rahales por parte del Estado, a pesar de seguir habiendo zonas reservadas para las aljamas campesinas. Finalmente, está claro que estos espacios pantanosos no pueden ser considerados marginales, pues cada vez hay más pruebas que confirman su importancia económica, tanto para las comunidades campesinas -tribales o no- como para los propietarios de los rahales pertenecientes a la aristocracia estatal. Es mucho, pues, lo que queda por saber e investigar al respecto, porque solo hemos empezado a arañar conocimiento y hay que plantear, comprobar o descartar aún muchas hipótesis.

\section{REFERENCIAS BIBLIOGRÁFICAS}

Almagro-Gorbea, M. (2001). La Serranía de Albarracín. Análisis etno-arqueológico de la ganadería en la Celtiberia meridional. En J. Gómez-Pantoja (Ed.), Los rebaños de Gerión. Pastores y trashumancia en la Iberia antigua y medieval (pp. 233-262). Madrid: Casa de Velázquez.

BAzZANA, A. (1992). Maisons d'al-Andalus: Habitat médiéval et structures de peuplement dans l'Espagne orientale. Madrid: Casa de Velázquez.

BosCH VILÁ, J. (1959). Historia de Albarracín y su sierra. Tomo II, Albarracín musulmán. Teruel: Instituto de Estudios Turolenses.

CARA BARRIONUEVO, L. (2009). Huellas de pastores. Observando los paisajes ganaderos de los «extremos» granadinos. En A. Malpica (Ed.), Análisis de los paisajes históricos: De al-Andalus a la sociedad feudal (pp. 169-202). Granada: Alhulia.

Cortés, J., Furió, A., Guichard, P. y PONS, V. (1981). Les alqueries de la Ribera. Assaig d'identificació i localització. En Economia agrària i història local. I Assemblea d'Història de la Ribera (pp. 209-262). Valencia: Alfons el Magnànim.

DomínGueZ, P. (2017). El agdal, el gran sistema de gestión comunitaria de los recursos naturales del Magreb y... idel extremo sud-occidental de la Europa medieval?. En S. Villar y M. García (Eds.), Ganadería y arqueología medieval (pp. 143-169). Granada: Alhulia.

Esquilache, F. (2018). Els constructors de l'Horta de València. Origen, evolució i estructura social d'una gran horta andalusina entre els segles VIII i XIII. Valencia: Publicacions de la Universitat de València.

FERRANDO, A. (1979). Llibre del Repartiment de València. Valencia: V. Garcia editors. Furió, A. y MARTíNEZ, L.P. (2006). La evolución histórica del regadío en la Ribera Baixa del Xúquer. Margen izquierdo. En J. Hermosilla (ed.), Las Riberas del Xúquer: paisajes y patrimonio valencianos (pp. 206-218). Valencia: Universitat de València. 
GARCIA-Oliver, F. (2003). La vall de les sis mesquites. El treball i la vida a la Valldigna medieval. Valencia: Publicaions de la Universitat de València.

García, M. y Moreno, M. (2018). De huertas y rebaños: reflexiones históricas y ecológicas sobre el papel de la ganadería en al-Ándalus y aportaciones arqueozoológicas para su estudio. Historia Agraria, (76), 7-48. https://doi.org/10.26882/histagrar.076e01g

García García, M., Moreno, M., Fuertes, M.C. y Hidalgo, R. (2021). Por sus basuras los reconoceréis: La identificación arqueozoológica de una comunidad dimmí cristiana en la Qurțuba tardoandalusí (Cercadilla, siglo XII). Arqueología y Territorio Medieval, (28), 57-97. https://doi.org/10.17561/aytm.v28.5797

GONZÁLEZ VILLAESCUSA, R. y KiRCHNER, H. (1997). La construcción d'un espai agrari drenat andalusí al hawz de la Madina de Yabisa. Anàlisi morfológica, documental i arqueológica del Pla de Vila. En M. Barceló (Ed.), El curs de les aigües. Treballs sobre els pagesos de Yabisa (pp. 65-95). Ibiza: Consell d'Eivissa i Formentera.

Guichard, P. (1969). Le peuplement de la région de Valence aux deux premiers siècles de la domination musulmane. Melanges de la Casa de Velázquez, (5), 103158. https://doi.org/10.3406/casa.1969.994

GuichaRD, P. (1980). Toponymie et histoire de Valence à l'époque musulmaneun chef berbère valencien du IXe siècle à la conquête de la Sicile?. En Primer Congreso de Historia del País Valenciano (pp. 399-409). Valencia: Universitat de València.

Guichard, P. (2001). Al-Andalus contra la conquista cristiana. Valencia: Publicacions de la Universitat de València.

Guinot, E. (1991). Cartes de poblament medievals valencianes. Valencia: Generalitat Valenciana.

GutiéRREZ, S. (1995). El origen de la huerta de Orihuela entre los siglos VIII y XI. Una propuesta arqueológica sobre la explotación de las zonas húmedas en el Bajo Segura. Arbor, (593), 65-94.

Horden, P. y Purcell, N. (2000). The Corrupting Sea: A Study of Mediterranean. Oxford: Blackwell.

Malpica Cuello, A. (2013). Organización del territorio y estructuras económicas en la frontera nororiental del reino de Granada. En S. Villar (Ed.), Sal, agricultura y ganadería: La formación de los paisajes rurales en la Edad Media (pp. 19-41). Granada: Universidad de Granada.

Malpica Cuello, A., Villar, S. y García-Contreras, G. (2017). Paisajes ganaderos en las últimas tierras de al-Andalus. En S. Villar y M. García (Eds.) Ganadería y arqueología medieval (pp. 99-125). Granada: Alhulia.

Malpica Cuello A. y García-Contreras, G. (2019). La gestió de l'aigua en les zones humides de l'actual Andalusia en época andalusina. Afers. Fulls de recerca i pensament, (93), 409-434. 
Moreno, M. (2004). Musulmanes y cristianos en la sierra de Albarracín (Teruel): una contribución desde la Arqueozoología para la historia de la trashumancia. En J. L. Castán y C. Serrano (Eds.), La trashumancia en la España mediterránea (pp. 235-262). Zaragoza: CEDDAR.

Ortega, J. (2018). La conquista islámica de la Península Ibérica. Una perspectiva arqueológica. Madrid: La Ergástula.

Parra, M. (2019). Sobre l'origen de l'Horta d'Oriola. Regadiu i espais agrícolas andalusins a la Vega Baixa del Segura. (segles VIII-XI). Afers. Fulls de recerca $i$ pensament, (93), 311-344.

Peñarroja, L. (2013). Historia de Vall d'Uxó. Castellón de la Plana: Diputació de Castelló.

Ramos, J.R. (1988). Política ganadera de los Reyes Católicos en el Obispado de Málaga. Málaga: Diputación de Málaga.

Rosselló, V. (1979). Els espais albuferencs al País Valencià. Acta Geológica Hispánica, (14), 447-483.

RoYo, V. (2020). Ganadería e integración del espacio regional: la organización y la gestión de las pasturas en las fronteras de la Corona de Aragón, siglos XII-XIV. Historia Agraria, (80), 7-36. https://doi.org/10.26882/histagr.080e01r

TORRó, J. (1998). La colonización del valle de Pego (c. 1280-c. 1300). Prospección y estudio morfológico: primeros resultados. Arqueología Espacial. Arqueología del Paisaje, (19-20), 443-461.

TORRó, J. (2016). Agricultural drainage technology in medieval Mediterranean Iberia (13th-16th centuries). En J. Klapste (Ed.), Agrarian Technology in the Medieval Landscape (pp. 309-323). Turnhout: Brepols. https://doi.org/10.1484/M. RURALIA-EB.5.110474

TORRÓ, J. y ESQUiLACHE, F. (2018). 'Por donde jamás habían sido conducidas aguas'. La transformación agraria del marjal norte de la Albufera de Valencia (siglos XIIIXV). En J. Torró y E. Guinot (Eds.), Trigo y ovejas. El impacto de las conquistas en los paisajes andalusies. Siglos XI-XVI (pp. 161-225). Valencia: Publicacions de la Universitat de València.

TRILlo, C. (2004). Agua, tierras y hombres en al-Andalus. La dimensión agrícola del mundo nazarí. Granada: Tharg.

VERCHER, S. (2006). Los fundamentos del regadío histórico tradicional en la Ribera Baixa del Xúquer: el margen derecho. Siglos XIII-XX. En J. Hermosilla (ed.), Las Riberas del Xúquer: paisajes y patrimonio valencianos (pp. 219-237). Valencia: Universitat de València.

VIRGILI, A. (2010). Espacios drenados andalusíes y la imposición de las pautas agrarias feudales en el Prado de Tortosa (segunda mitad del siglo XII). En H. Kirchner (ed.) Por una arqueología agraria. Perspectivas de investigación sobre espacios de cultivo en las sociedades medievales (pp. 147-155). Oxford: Archaeopress. 